\title{
RESENHA DE ESSE AIRES, ORGANIZADO POR ABEL BARROS BAPTISTA, CLARA ROWLAND E PEDRO MEIRA MONTEIRO
}

REVIEW OF ESSE AIRES, EDITED BY ABEL BARROS BAPTISTA, CLARA ROWLAND AND PEDRO MEIRA MONTEIRO

BAPTISTA, Abel Barros; ROWLAND, Clara; MONTEIRO, Pedro Meira (Orgs.). Esse Aires. Peixe-elétrico Ensaios, 2020. 130p.

\section{ANDRÉ CORRÊA DE SÁ}

University of California, Santa Barbara

Santa Bárbara, Califórnia, Estados Unidos

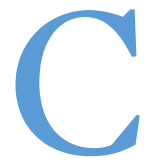

omo evidencia Hélio de Seixas Guimarães em Machado de Assis, o escritor que nos lê (2017), Machado de Assis nunca deixa de interrogar o leitor. O mesmo é dizer: não somos capazes de dominar Machado - ao contrário, é ele que nos domina. Não espanta, portanto, que a tradição crítica em torno de Machado seja marcada por momentos de descontinuidade, que reanimam constantemente o debate em torno da sua obra. Em resultado, os consensos são sempre precários, mesmo entre os seus apologistas. Periodicamente somos apresentados a uma figura predicada de maneira diferente e a propostas de reorientação dos estudos machadianos. Isto quer dizer que, num sentido pragmático, por mais que as nossas convicções intuitivamente nos aproximem de certas explicações particulares, a imagem de Machado tende a ser relacional, provisória e nominalista. O leitor nunca deixa de se confrontar com a possibilidade de estar a usar os termos e os pressupostos errados nas interpretações que toma como válidas e úteis. Por isso, dependendo dos credos críticos e das ideias sobre os seus livros de que nos fazemos acompanhar, essas figuras, não raro contrastantes e até contraditórias, podem parecer-nos lúcidas e familiares ou estranhas e exasperadamente confusas. 
De um ponto de vista técnico, talvez se possa dizer que as discussões sobre a natureza do realismo de Machado têm propiciado e reanimado algumas das discussões mais interessantes da literatura brasileira. Há notáveis exceções a essa regra geral, mas, simplificando muitíssimo um debate necessariamente diverso e intricado, os críticos podem distinguir-se entre aqueles que demonstram que Machado esposa uma visão crítica do processo histórico brasileiro, aqueles que, pelo contrário, insistem no putativo desajustamento das suas ideias em relação à "experiência nacional" e aqueles que enaltecem a universalidade do seu humanismo.

As perguntas que em cada um desses momentos se formulam e a pletora de respostas que daí decorrem têm, notoriamente, produtividades distintas. Só para dar o exemplo de dois casos paradigmáticos, enquanto a censura de Mário de Andrade ao caráter estrangeirado de Machado envelheceu mal, a interpretação de Roberto Schwarz, mostrando que romances como Brás Cubas podem ser usados para denunciar as contradições da estrutura social brasileira, parece terse instalado definitivamente no vocabulário crítico. O certo é que, ao longo das últimas décadas, a obra de Machado - basta compararmos as leituras de Schwarz, John Gledson e Alfredo Bosi para ter uma ideia da amplitude das discussões que se desenvolvem - tem demonstrado que ainda estamos longe de esgotar os recursos argumentativos e os jogos de linguagem a que podemos recorrer.

Esse Aires, organizado por três especialistas de créditos firmados nos estudos brasileiros - Abel Barros Baptista, Clara Rowland e Pedro Meira Monteiro -, é mais um desses momentos de excitação intelectual que as tentativas de releitura de Machado nos têm proporcionado. Um momento, acrescento, que é a vários títulos excepcional. Trata-se da reunião de sete estudos, rematados com um posfácio, da autoria de autores brasileiros e portugueses, dedicados ao legado literário do Conselho Aires, o velho diplomata aposentado que regressa ao Brasil depois de longos anos no exterior e se entretém a registar observações sobre os seus dias numa série de cadernos manuscritos (o célebre Memorial). Como se sabe, o Conselheiro Aires surge primeiramente em Esaú e Jacó (1904), como autor do caderno do qual se extraiu a narrativa autónoma que deu origem ao romance, e, mais pronunciadamente, em Memorial de Aires, de que é autor, narrador e personagem principal. Mesmo que dois dos ensaios incluídos neste volume incidam sobre Esaú e Jacó, o Memorial constitui, sem dúvida, o centro gravítico deste volume. Abel Barros Baptista e Clara Rowland, em forma dialogada, abrem 
o volume, a duas vozes, e Hélio de Seixas Guimarães assina o posfácio que, resumindo e pondo em perspetiva os contributos de cada um dos ensaios anteriores, nos ajuda a colocá-los na cena crítica machadiana. Entre estes dois momentos, alinham-se ensaios de Humberto Brito, Joana Matos Frias, Amândio Reis e Pedro Meira Monteiro (que examinam o Memorial) e de Ariadne Nunes e Luciana Antonini Shoeps (que examinam Esaú e Jacó).

O gesto revisionista que motivou o colóquio de que resultou este volume é desde logo sugerido pela natureza oblíqua do título, a que voltarei. Como bem se sabe, Memorial de Aires, publicado às vésperas da sua morte, é o último romance de Machado de Assis. Em 1908, Machado, presidente da Academia Brasileira de Letras, era unanimemente considerado o maior escritor do seu tempo. Também sabemos isso. Presumivelmente, teria pensado terminar a carreira com Esaú e Jacó - o título preliminar era justamente "Último" -, mas as provações pessoais trazidas pela morte repentina da sua meiga Carolina e pela iminência do seu próprio desaparecimento e a melancolia que envolvia a sociedade brasileira desse tempo ter-lhe-ão solicitado que perfilhasse um último título.

Memorial de Aires tem sido correntemente descrito como o sucedâneo desse momento duplamente crepuscular. Voltando a debruçar-se sobre os cadernos deixados pelo Conselheiro Aires, o organizador e editor, identificado pelas iniciais M. de A., explica na “Advertência” prévia que tratou de recolher e mandar imprimir, desta vez, uma seleção das entradas correspondentes aos anos de 18881889, preterindo as que não articulassem "o mesmo assunto" numa "narração seguida". Não é demais recordar que esse período, propositadamente escolhido pelo editor do volume quase uma década depois e evocado com a costumeira ironia machadiana, corresponde aos anos cruciais do Brasil oitocentista em que a abolição foi aprovada e a monarquia deu lugar ao regime republicano. Como sugere Hans Ulrich Gumbrecht (2014, p. 120), a atmosfera desse momento histórico emerge no Memorial sob forma de uma tristeza tropical que, pelo menos desde Lévi-Strauss, já se converteu numa espécie de truísmo.

$\mathrm{O}$ romance foi bem-recebido pelos seus pares, que decerto se sentiram gratificados pela oportunidade de vislumbrarem sob as máscaras do Conselheiro Aires e do casal Aguiar a vida íntima de Machado e, particularmente, uma comovente homenagem a Carolina. Todavia, do conjunto dos grandes romances da segunda fase de Machado, a que indiscutivelmente pertence, foi também este o mais negligenciado pela crítica. John Gledson, no seu importante livro sobre a 
relação entre ficção e história na obra de Machado, observou que a legibilidade do Memorial é afetada pelo aparente despojamento do enredo. Os acontecimentos, os pensamentos e as observações de Aires são registados de forma lenta e sinuosa, dando a sensação de que o velho Conselheiro, numa fase da vida em que perdona a tutti, não tem paciência para dar mais do que isso ao leitor. Quando comparado com os congéneres, argumenta Gledson, o estilo compositivo do Memorial pode ser desencorajante.

Embora reconheça que algumas passagens, pela natureza particularmente lenta e truncada deste diário, possam ser exasperantes, Gumbrecht, por seu turno, assinala que o Memorial tem o mérito de explorar sistematicamente a possibilidade de levar a bom porto o projeto flaubertiano de escrever um "livro sobre nada". Em retrospetiva, talvez a aderência dos contemporâneos à derradeira floração de Machado tenha sobretudo espelhado a reverência com que era agraciado o maior escritor do Brasil, mais do que o reconhecimento dos méritos do último romance do mestre.

O que desde logo chama a atenção do leitor é que, embora os vários capítulos de Esse Aires sejam em termos substantivos muito diferentes uns dos outros, as leituras que oferecem do Memorial de Aires partilham uma série de afinidades eletivas. Essas afinidades, por um lado, põem em evidência a nossa incapacidade para escapar a questões técnicas complicadas induzidas pelo estilo de Aires, como a permanente tensão genológica entre diário e narrativa. Por outro lado, põem em evidência que as explicações que Aires nos oferece da sua própria experiência são deliberadamente difusas e obscuras. Ao mesmo tempo, todos nos sugerem que o valor de originalidade do Memorial é inseparável do edifício que essa direção compositiva produz.

A forma de diário é um problema que os cinco ensaios sobre o Memorial endereçam com minúcia. O diálogo entre Abel Barros Baptista e Clara Rowland, intitulado "I can not etc.", põe em cima da mesa um conjunto de ideias que, em termos mais ou menos explícitos, constituem uma espécie de propedêutica cujos eixos principais são desenvolvidos nos restantes ensaios. Baptista lança o repto para a conversa com um astucioso comentário sobre a entrada de 8 de abril (a primeira entrada do diário tem data de 9 de janeiro), que principia com a frase "Papel, amigo papel, não recolhas tudo o que escrever esta pena vadia". Jogando com a distinção entre diário e romance e abrindo as perspetivas críticas sobre o ato de escrita e o estilo do Memorial, o ponto alto do diálogo está na discussão 
sobre o modo como o verso de Shelley "I can give not what men call love", que atravessa todo o livro, pode ser visto como uma abreviatura da relação quiasmática que Aires mantém com a vida, com o tempo e com o próprio ato da escrita.

As dúvidas em relação ao modo como devemos usar o Memorial são também discutidas por Humberto Brito em "A expressão sem nome". Depois de sublinhar que o Memorial elabora, obviamente pela última vez, duas das ideias fixas de Machado, Brito chama atenção para uma série de "paridades, simetrias, repetições e coincidências" presentes na narrativa e sugere que o Memorial poderia ter sido escrito (de modo que poderá com vantagem ser lido) do fim para o princípio, a partir da imagem dos "dois velhos sentados, olhando um para o outro", que, em retrospetiva, satura a atmosfera do romance com esse sentimento de "orfandade às avessas". Recomendando implicitamente que se ponha em prática a lógica da "reforma dramática” proposta por Bento Santiago, Brito argumenta que só essa cena de intimidade conjugal nos permite identificar claramente o Conselheiro Aires com Machado de Assis.

Encontrando um "princípio discursivo macunaímico" nos gestos indolentes com que Aires vai anotando os seus dias, Joana Matos Frias, em "Das negativas: preterição e ventriloquacidade no estilo Aires", retoma uma menção velada a Bartleby que aparece no diálogo entre Baptista e Rowland para mostrar, com o rigor e a inteligência habituais, que a estrutura enunciativa do Memorial consiste, em grande medida, numa exploração em larga escala do "exercício das negativas" através do recurso a "paralipses e paralepses, anáforas e catáforas".

Em "A vida é um ofício cansativo: biografia, escrita e apagamento em Memorial de Aires", Amândio Reis retoma a ideia de lacuna para argumentar que o acesso do leitor ao Memorial de Aires - a totalidade do conteúdo dos cadernos manuscritos - se dá por intermédio do Memorial de Aires, uma versão antológica de um arquivo maior. Produzida pela rasura do material que o outro acumulara, a versão antológica que o leitor conhece está orientada por um "duplo movimento [...] entre expressão e rasura".

Tanto Ariadne Nunes quanto Luciana Antonini Schoeps, autoras, respetivamente, de "'Pare no D'. Alguns nomes em Esaú e Jacó" e "Aires e as rasuras do manuscrito de Esaú e Jacó: vozes sem pai e o defunto autor entre a literatura e a democracia", se debruçam sobre o manuscrito autógrafo de Esaú e Jacó, recentemente disponibilizado no site da Academia Brasileira de Letras, que 
comparam e contrastam com a edição da Garnier de 1904. Descrevendo-nos alguns detalhes do caminho de reconstrução do manuscrito autógrafo que Machado foi percorrendo antes de o entregar aos prelos, os dois ensaios chamam a atenção para o facto de que certas hesitações e rasuras nos oferecem pistas para compreender melhor as virtudes do seu universo ficcional. Através da leitura de alguns episódios que tematizam a questão do nome próprio, Ariadne Nunes sugere que olhemos com especial atenção para a teia de significados que origina. Por sua vez, Luciana Antonini Schoeps sugere que as várias correções pelas quais passou o manuscrito denotam a intenção de adensar, por meios democráticos, o emaranhado de vozes ficcionais. Ambas as autoras recomendam que o leitor abandone a esperança de encontrar frases e situações inequívocas e se obrigue, a todo o momento, a perguntar a si mesmo: "Quem é que fala?".

Antecedendo o posfácio, o ensaio de Pedro Meira Monteiro, "Minados pelo tempo: o sujeito e o instante no Memorial de Aires", um dos mais instigantes do volume, leva a cabo uma competentíssima e penetrante discussão sobre o sujeito na ficção de Machado. Convocando o potencial da cultura pós-hermenêutica descrita por Gumbrecht, em detrimento do vocabulário do excepcionalismo antropocêntrico de matriz ocidental, a reflexão de Meira Monteiro desdobra-se em dois planos. Primeiro, reexamina a genealogia do "pessimismo" machadiano à luz dos efeitos de presença induzidos pela experiência estética. Depois, em diálogo implícito com Roberto Schwarz e Sidney Chalhoub, mostra que, especialmente num caso como o de Aires, a tentativa de ir além da busca do sentido pode justamente abrir espaço para tecer novas interrogações em torno da relação de Machado com a história social brasileira.

No conjunto, os ensaios coligidos em Esse Aires evidenciam a irredutibilidade de Machado a qualquer tentativa de enquadrar os seus livros em descrições objetivas e ubíquas. O deíctico do título, que cada ensaio reelabora à sua maneira, envia-nos para esse desconcertante território, sempre intermédio, do autor que, falando de si, fala primordialmente de «nós». Lembrando que nenhuma das explicações de Machado tem um desfecho, Hélio Guimarães tem insistido na ideia de que a força hegemônica de Machado de Assis nas letras brasileiras se revela no modo como é capaz de inverter o enlace entre autor e leitor a favor do primeiro. Este livro, cujo aparecimento saúdo, desenvolve algumas consequências dessa noção. 


\section{Referências}

GUIMARÃES, Hélio de Seixas. Machado de Assis, o escritor que nos lê. São Paulo: Editora Unesp, 2017.

GUMBRECHT, Hans Ulrich. Atmosfera, ambiência, stimmung: sobre um potencial oculto da literatura. Tradução de Ana Isabel Soares. Rio de Janeiro: Contraponto/Editora PUC Rio, 2014.

ANDRÉ CORREA DE SÁ é professor de literatura portuguesa e literaturas africanas de língua portuguesa na Universidade da Califórnia em Santa Barbara. Além de vários artigos sobre autores dos espaços luso-afro-brasileiros, é autor de Depressão e psicoterapia em António Lobo Antunes: qualquer coisa que me ajude a existir (Texto, 2019) e co-organizador de Mike Tyson para Principiantes (Assírio \& Alvim, 2017). Atualmente, os seus interesses de pesquisa focamse nas relações entre a literatura e o ambiente.

(iD) https://orcid.org/0000-0002-6468-745X. E-mail: acorreadesa@ucsb.edu

Recebido: 09.11.2020

Aprovado: 15.11.2020 